\title{
Strategies for Dealing with Gang Activity in Urban Communities
}

\author{
Phillip Neely \\ Saint Leo University
}

\begin{abstract}
As disturbing as youth and gun violence is, it is not hard to reduce the mortality rate because it is preventable. The information provided in this research will help to get policies waiting to be reviewed by legislators, and any new proposal that reaches the appropriate legislative chamber, reviewed without obstacles and will help to prevent youth violence. Upon completion of this research, the study shows that rates of youth violence have decreased based on programs implemented at the state government level with a stronger juvenile justice system holding offenders accountable to ensure public safety and reduce youth violence and victimization. The study shows that community and school involvement with law enforcement and government agencies are some of the strategies needed to help reduce gun violence and rebuild communities.
\end{abstract}

Keywords: gang activity, urban communities, juvenile delinquency, violence

\section{Introduction}

The use of guns among youth is the second leading cause of death among children between the ages of 10 and 19 in the United States (Office of Juvenile Justice and Delinquency Prevention [OJJDP], n.d.). Despite programs implemented to get children involved in extracurricular activities, keep them motivated to stay in school, and help make communities safe again, more than 20,000 youth are injured or killed by guns every year (OJJDP, n.d.). The juvenile justice system is facing an increase in violent crimes committed by juveniles and an increase in abuse, neglect, and gun violence. No place in the United States is safe from the increasing levels of criminal violence. The scope of the problem involves all of American society and the focus should not be on only one or two areas. This study will involve examining existing programs with proven youth violence reduction outcomes and examining new programs for effectiveness.

According to Wolseth (2011), the primary question is basic to strategizing ways to gain control of violence among youth. The question is how to identify, put into practice, and advance programs intended to stop delinquency. Solving this issue will require involvement from families, schools, communities, and related organizations to be successful in reducing violent acts of crime. Homicides are a result of severe physical attacks deriving from threatening behavior due to bullying from juveniles in schools and various communities. People behave in a violent manner for many reasons; therefore, it may be difficult to determine the logic of such behavior.

Gangs and gang members have existed for decades, at least as far back as the Little Rascals television show that aired on Saturday mornings in the late 1930s. Many people are not aware that the show was based on two groups of children who did not like each another, and whenever one group would cross the other group's

Phillip Neely, Ph.D., associate professor, Department of Public Safety Administration, Saint Leo University, USA; main research fields: Public Policy and Criminal Justice and Management. 
path, they would begin a fist fight. The only person that rivals Spanky and Buckwheat liked was the little girl Darla.

After gang members initiate new members, they will move their criminal activities to the neighborhood community, where they will incorporate more members and perhaps go on a crime spree. Any location where there is a group of kids, such as parks and teen clubs, can also be a high-risk area for vulnerable teens to be easily intimidated, and that teens can become an easy target for being recruited into gangs.

Gang members commit crimes in city schools by bullying students who do not cooperate with attempts to initiate them into a gang. Several resources have been delegated to the juvenile justice system, including gang units and independent intervention programs. Gangs in city schools are out of control, but now the police department has orchestrated a special gang unit to find solutions on stopping gang activities that were occurring in the schools and in the community (Wolseth 2011).

\section{Literature Review}

Sheppard, Grant, Rowe, and Jacobs (2002) noted the OJJDP enforced a program that would contribute to the prevention and intervention of juvenile violence. One of the main goals of the OJJDP is to decrease unauthorized access to firearms by youth. A second goal is to reduce the number of juveniles who carry illegal guns and commit crime. The OJJDP emphasizes the seriousness of gaining the attention of youth through stiff punishment when they commit crimes with firearms. The OJJDP has created seven steps to ensure the successful execution of the policies. The OJJDP working closely with law enforcement will reduce how people exchange illegal firearms and provide applicable intervention programs to repeat offenders. The justice system is overwhelmed with the amount of work needed to control gangs and the crimes they commit. The judicial system must implement critical avenues that will decrease gangs and gang activity that starts in schools.

Young children in first grade and kindergarten are looked upon as vulnerable potential victims who become traumatized due to fear. "Gangs began as early as elementary school where kids have gang symbols on their book bags; they will also bring weapons to school such as knives to show old members a way for recruitment” (Beauregard 2013, 101).

Criminal activity is key to gang member and the members are not easily scared; therefore, precautionary measures will need to remain in effect. However, lawmakers are not considering the crimes committed to be a threat, but are catching those who participate in criminal activities and punishing them to the fullest extent of the law. Several past practices have resulted in policing strategies being unsuccessful in decreasing the crime rate. Moreover, many policing strategies have minimal support from physical patrols in the community, although there has been a small increase in the physical presence of the police, including some arrests made on the spot. An immediate answer to a call could contribute to a decrease in crime.

Many of the perpetrators in the community have no respect for the law, which creates a challenge for the police as they attempt to keep order. The behavior of the perpetrators challenges the police department to develop a process that will benefit the citizens and gain respect for law and order.

Leaders of police departments throughout the United States have developed and are currently implementing policing strategies that will be productive with a positive outcome. Accomplishing this method involves using hot-spot policing and directed patrols. Although much of the assistance for the strategies used comes from using geographic information systems, artificial intelligence, and crime analysis, past methods that involved manually pinpointing areas on a map limited progress. However, current technology has provided the 
opportunity to calculate the progression of crimes and their locations over a widespread area.

Artificial intelligence is a type of knowledge acquired through experience and the application of scientific knowledge. The main purpose of artificial intelligence is to create computers that will operate with a focus on being able to exercise thought, sight, sound, touch, speech, and the ability to move on foot. Artificial intelligence can be developed through the manifestation of physical presence and mind power. The main research areas in which artificial intelligence can be used are the applications of natural language, robotics, computer science, and cognitive science applications. However, natural language application is a system that uses voice commands programmed into a computer with specific instructions.

The computer science application is a system that develops advanced and future generation of mainframe computers with the capability of functioning like the human brain. Furthermore, the cognitive science applications tend to mimic the influential mind-set of the human brain. The expert systems in the cognitive science application have allowed the police to rely on its positive results.

The five innermost parts of operational strategies of law enforcement are preventive patrol, routine incident response, emergency response, criminal investigation, and problem solving. Preventive patrol is used to display the presence of the police in hopes of deterring crimes from being committed while the police are patrolling the area. The routine incident response is the accountability of the police officer on duty throughout the day while making sure there are no false infractions being committed.

Criminal investigation is a process that involves gathering facts concerning an existing crime and making a decision with a possible result of arresting the unknown subject. Problem solving, which is referred to as problem-oriented policing, is a method where police officers try to improve their relationship between the residents, the communities they police, and other authorities. Problem solving can also be used as a type of unofficial mediation. As a result, the police officer on location can mitigate tensions between residents through discussions using reason.

The operational strategies used by police departments may vary depending on factors involving location, present crime rate, the top crime committed, the area in which the crimes are being committed, and the situation. Moreover, researchers have shown that having a single set of strategies is ineffective and dangerous. Therefore, police departments choose to make changes by adapting to the situation based on where they are, the kind of situation they are handling, and the kind of crime they are trying to prevent.

Policing strategies have evolved over the past few decades and are continuing to do so. One reason for this is the introduction of modern technology to the police force. Having two way radios and computers installed in police vehicles allows for a strategy called intelligence-led policing. Police officers can now be more aware of both crime and criminals in their surrounding area. After police officers receive intelligence from headquarters, they can choose to employ problem-oriented policing, which is another strategy that allows police officers to shift tactics, depending on the problem.

Police officers began to show how they were more closely committed to working with communities in crime prevention during the 1990s. The police officers were also working on various strategies to include broken windows policing. This strategy involves managing areas that represent a place to breed crime. Fixing broken windows and removing graffiti will make abandoned properties less likely to draw unwanted attention from individuals looking to commit illegal activities. Policing strategies can help eliminate the fear of crime among residents who choose not to become involved and lock themselves in their homes. Fear tends to grip the residents, causing them to fear repercussions from the perpetrators who have little to no respect for the law. 


\section{Methodology}

The three demographic variables Blumstein (2013) included in his findings were age, race, and gender. Youth who are a part of the drug market usually carry guns for their own protection. Guns are used in this market to resolve conflicts regarding a drug dispute (Blumstein 2013). Most youth who participate in distributing and selling drugs live in inner-city neighborhoods. According to Blumstein, urban African-American juveniles (8) see no other means of economic success, so they turn to the drug market for income.

Characteristics of violent youth and the patterns that contribute to this type of violence include the influence of family violence and factors such as depression, aggressive behavior, and violence in the media. Youth are exposed to violence in a number of places, including schools, homes, and communities. Extensive exposure to violence and aggressive behavior causes youth to commit acts of violence as well. Most youth tend to mimic what they see in the home, schools, community, or media.

\section{Findings}

The findings showed that violent acts committed in the home, at school, and from video and television, show influence most youth. Data have shown that several violent crimes were committed by non-homicidal juveniles evaluated using the same types of characteristics. Some of the results showed that homicidal youth did not reveal any psychological disorders, but some of the data showed similarities in stress, access to weapons, and limited family involvement. The data did not indicate whether juveniles raised by someone other than their parents had any role in developing homicidal traits. The sampling method involved reviewing prior cases in which some juveniles were accused of crimes and trying to show a link between certain methodological comparisons. A more distinctive measure could have been found by not focusing on intellectual and social factors of each juvenile, as some of the youth assessed had a comparatively high IQ.

\section{Conclusion}

Collaborative community efforts are constructive responses to creating caring communities and expanding the safety net for children, youth, and families. The goal of community collaboration is to get individuals and members of community agencies and organizations together in a supportive environment to solve existing and increasing problems methodically that might not be solved by one group alone. In urban communities, it is advantageous and essential to build community collaborative groups to address public health issues (Wolseth 2011).

The aftermath of gangs committing crimes is communities devastated by drive-by shootings, as well as intimidation of children in schools, communities, and local businesses. Recent analysis based on a potential gang activity led the leaders of one local mall in DeKalb County to require teens under the age of 18 to be with an adult on weekends. If teens are not with an adult, then the police will question them and the officer will decide what to do with them. Police are trying to prevent crime by not just gang members but any criminal who feels like participating in criminal activity. Metropolitan police department in the Atlanta area have created special gang units to help with the juvenile gang issues.

Parents should observe their children's media use, including computers and video games. It is possible that every child in the United States is exposed to gun violence through media coverage of shootings, films and television programs, and aggressive games that allow young people to fire at targets on the screen. Youth still 
commit violent crimes frequently; whether homicide, suicide, or unintentional, most are committed due to having access to a firearm.

\section{Works Cited}

Blumstein, Shelia and Dima Amso. "Neural Plasticity and Dynamic Functional Organization: Insights from Functional Neuroimaging.” Perspectives on Psychological Science 8 (2013): 44-48.

Linda, Chan, Michele Kipke, Arlene Schneir, Ellen Iverson, Curren Warf, Mary Ann Limbos, and Paul Shekelle. "Preventing Violence and Related Health-Risking Social Behaviors in Adolescents.” Evidence Report/Technology Assessment 107 (2004): $1-7$.

Michael, Foucault, Scott Morse, Hubertus Oosterhuis, Roy Porter, Mikulas Teich, Nicole Rafter, and Anderew Scull. "Preventing Gang Violence.” Philosophy, Psychiatry \& Psychology 15 (2008): 17-78.

Charles, Swanson, Leonard Territo, and Robert Taylor. Police Administration, Structures, Processes, and Behaviors. 8th ed. Upper Saddle River: Pearson Education, 2012.

Jon, Wolseth. Jesus and the Gang: Youth Violence and Christianity in Urban Honduras. Tucson: University of Arizona Press, 2011. 